University of New Hampshire

University of New Hampshire Scholars' Repository

Philosophy Scholarship

Philosophy

4-1988

\title{
Hegel on Reference and Knowledge
}

Willem A. deVries

University of New Hampshire, willem.devries@unh.edu

Follow this and additional works at: https://scholars.unh.edu/phil_facpub

Part of the Philosophy Commons

\section{Recommended Citation}

"Hegel on Reference and Knowledge," Journal of the History of Philosophy, Vol. XXVI, No. 2 (April 1988), pp. 297-307

This Article is brought to you for free and open access by the Philosophy at University of New Hampshire Scholars' Repository. It has been accepted for inclusion in Philosophy Scholarship by an authorized administrator of University of New Hampshire Scholars' Repository. For more information, please contact

Scholarly.Communication@unh.edu. 


\section{Notes and Discussions}

\section{Hegel on Reference and Knowledge}

Hegel claimed that the object of thought is the universal. Since knowledge involves thought, this seems to imply that knowledge of particulars, or what Hegel called individuals, is impossible. But careful distinctions must be made before this interpretation of Hegel can be endorsed. I would like to look more closely at an argument commonly supposed to support this thesis and show that what is really at issue is the immediacy of our knowledge of individuals, i.e., whether we have any knowledge of individuals that is not mediated by universals. In this argument Hegel denies only that we have any immediate knowledge of individuals. How a denial of the possibility of knowledge of individuals must be interpreted in Hegel's system will be discussed briefly in the final sections of this paper, when the role of reference in knowledge is explored more fully. While the discussion here will focus on such linguistic items as names and demonstratives, there are crucial philosophical questions about the nature of meaning and knowledge which hang in the balance.

The argument of Hegel's with which I am primarily concerned occurs in the first chapter of the Phenomenology of Spirit,' "Sense-Certainty." Sense-certainty is the attitude that takes true knowledge to be the immediate presence of an object to consciousness, eschewing all categorization. But, Hegel replies, any attempt to express one's knowledge involves categories, even the use of such apparently non-categorial words as 'this', 'here', and 'now'. Since knowledge must be expressed if it is to be preserved or communicated, expressibility is a necessary condition of knowledge, for we could hardly call something knowledge that could neither be remembered nor communicated. Such a categorially impoverished word as 'this' expresses the poorest, rather than the richest and truest, form of cognition. However rich the sensuous manifold may be, it does not itself constitute any kind of knowledge.

The above is but a rough sketch, but my first concern here is with why a certain interpretation and kind of reply to this argument will not work. We can find this interpretation and reply in at least four places in the contemporary literature. ${ }^{2} \mathrm{D}$. W.

1 References to Hegel's texts have been abbreviated in the body of this paper. The following editions were used: Hegel's Phenomenology of Spirit, trans. A. V. Miller (Oxford: Oxford University Press, 1977), abbreviated as $P h S$, and Phänomenologie des Geistes, ed. J. Hoffmeister, 6th ed. (Hamburg: F. Meiner, 1952), abbreviated as PhG. Hegel's Science of Logic, trans. A. V. Miller (London: Allen and Unwin, 1969), abbreviated as SL; Wissenschaft der Logik, ed. G. Lasson (Hamburg: F. Meiner, 1934), Vol. 2, abbreviated as WdL.

- D. W. Hamlyn, Sensation and Perception: A History of the Philosophy of Perception (New York: Humanities Press, 1961), 140-46; Ivan Soll, An Introduction to Hegel's Metaphysics (Chicago: Univer- 
Hamlyn's statement of this interpretation is the earliest of these and is quite lucid. He takes the point of the argument to be that because demonstratives are universals, we cannot use them to refer to particulars, and because they do not successfully refer to particulars, knowledge phrased in terms of them cannot be knowledge of a particular. He then replies to the argument that such demonstratives, and proper names as well, for that matter, do indeed refer, and thus there is no problem about knowledge of particulars.

Words like 'red' are normally applied to many things predicatively; we use such words to characterize things. We do not normally use 'this' in that way, but in order to refer to things. The fact that we use the word 'this' to refer to a number of different things on different occasions does not show that it is like 'red' in its use. Words like 'this' were fastened on by Hegelians for the same reason as they were fastened on by their later opponents-e.g., Russell-because they were supposed to be the last ditch in a defence of knowledge of particulars. If these words did not guarantee particularity, what would? But the considerations which make it implausible to treat these words as general words of the same kind as 'red' apply equally to all those words which we use to refer to particular things, e.g., proper names. If we have, therefore, the means of referring to particulars, there seems no remaining objection to the view that we may have knowledge of particulars also.3

This interpretation of the argument is simply wrong: in the first section of this paper I show that Hegel does not deny that we can successfully refer to particulars, whether with names or with demonstratives. After discussing the relevant similarities and differences between names and demonstratives from Hegel's point of view, I shall discuss how Hegel's notion of the role of singular referential devices within knowledge is most plausibly construed. For this last part of the paper, contrasts with Russell's theory of acquaintance will be most illuminating, for we can understand Hegel's argument in the "Sense-Certainty" chapter as an attempt to destroy the belief that there can be knowledge of particulars by acquaintance.

Hegel's arguments that all knowledge of individuals must be mediated by universals are independent of his own proprietary and rather peculiar conception of a concrete universal. Every cognitive state involves relation to some universal, whether abstract or concrete; only the adequacy and richness of the cognitive state depend upon whether the universal is abstract or concrete. I shall therefore make no particular mention of the abstractness or concreteness of the universals involved in our cognitive states.

1.

Hegel does not deny that such terms as 'this' and 'here', or proper names, for that matter, can and often do successfully refer to individuals. The crucial question posed

sity of Chicago Press, 1969), 91-110; Gilbert Plumer, "Hegel on Singular Demonstrative Reference," Southwestern Journal of Philosophy (1980): 71-94; M. J. Inwood, Hegel (London: Routledge and Kegan Paul, 1983), 311-17.

3 Hamlyn, Sensation and Perception, 142-43. 
by Hegel in the "Sense-Certainty" chapter of the Phenomenology is "whether in sensecertainty itself the object is in fact the kind of essence that sense-certainty proclaims it to be; whether this notion of it as the essence corresponds to the way it is present in sense-certainty" ( $P h S, 59 ; P h G, 81$ ). The question is not, then, what the object is, or what predicates it takes, but whether it is the kind of object sense-certainty can get a grip on. The attitude of sense-certainty presupposes a certain view of the nature of objects and a view of the nature of the knowledge relationship that reveals the object to the knower. What fuels the dialectic here is the discrepancy between what sensecertainty believes knowing an object is and what sense-certainty can actually achieve.

But it is clear upon reading the rest of Hegel's argument that he never denies our ability to refer, but rather counts on our ability to refer to get his argument off the ground. If we ask "What is now?" we may (given that it is that time of day) correctly answer "Now is night." Hegel at no time denies the correctness of the reference here. Someone unfamiliar with Hegelian terminology might be tempted to think that he does deny this, for he immediately proceeds to question the truth of this assertion. But truth and correctness are not the same for Hegel.4 Questions of truth are questions about the agreement of something with its essence, the extent to which it lives up to its ideal. Sense-certainty believes that the here and now is the sole truth, the essence of objective experience. But, Hegel claims, "a truth cannot lose anything through our preserving it" $(P h S, 60 ; P h G, 81)$. If we take sense-certainty seriously, we find that "The Now that is Night is preserved, i.e. it is treated as what it professes to be, as something that is; but it proves itself to be, on the contrary, something that is not." For we have looked at the preserved assertion in the cold light of day. "The Now does indeed preserve itself, but as something that is not night" $(P h S, 60 ; P h G, 81)$. In other words, in each case the assertion successfully refers; in one case what it says is incorrect. Correctness is at least a necessary condition of truth, so the statement does not express something true. No single moment is the essence of the now, and the now is not the essence of any objective experience.

Hegel's mode of expression, as usual, is not overly transparent; but the basic point seems to me to be this: Their singularity, their very here-and-nowness, is what sensecertainty takes to be crucial to the objects of our experience, and correlatively, it takes knowledge to be direct presence or acquaintance. But this is a totally inadequate notion of what the essence of an object of our experience is, for if the object were exhausted by its presence to us, it would not be distinct from the experience of it. The object of experience goes beyond experience. Sense-certainty's inadequacy is sufficiently demonstrated by the fact that the most appropriate expression of immediate experience does not pick out the same object twice; it is impossible for sense-certainty to identify objects across experiences. Thus it is crucial to Hegel's arguments that 'this' can successfully refer now to a tree, now to a house, for it is precisely the inconstancy of the object it picks out that shows that 'this' is not an adequate expression for the essence of the objects of experience.

4 Soll seems not to notice the correctness/truth distinction in his rebuttal to Hegel's argument. 
We may put the point a slightly different way, I believe. The words 'this', 'here', 'now', etc., all demonstratives, do have meaning, however abstract or difficult to formulate exactly. And this meaning remains constant throughout all the uses of the terms. However, these terms play the role of non-characterizing, context-dependent, referring expressions. Thus, their actual reference is determined not just by their meaning, but also by the context of their use. Anything at all is a possible referent of 'this'; thus, in knowing something to be a 'this' one knows nothing at all about it. One gets beyond the uninformative 'this' only in the predicate of the judgment or in the contextual presuppositions of the act of referring.

2.

That this is Hegel's view receives support from the fact that he makes a similar argument about proper names. In considering a judgment like "God is the eternal," Hegel asserts "In a proposition of this kind one begins with the word 'God'. This by itself is a meaningless sound, a mere name; it is only the predicate that says what God is, gives Him content and meaning. Only in the end of the proposition does the empty beginning become actual knowledge" (Preface, $P h S, 12-13 ; P h G, 22)$. Any internally unstructured, pure referring expressions, such as proper names or demonstratives, are uninformative and empty according to Hegel.5

This position is not immediately evident, for it can be easily claimed that no isolated expression is informative. A predicate, such as 'red' or 'eternal', does not itself inform us of anything until it finds a position in a proposition; it seems to be no different from a pure referring expression in this regard. But this is going too far, for predicates are the predicates they are because of the relations they bear to other predicates. These relations include exclusion (e.g., between red and green), inclusion (e.g., between bachelor and man), and presupposition.

It is important to remember here that according to Hegel concepts are essentially the kind of thing that can play the role of a middle term in a syllogism. And what is essential about this role is the ability to unify the universal and the individual, represented by the major and minor terms. But syllogisms (or more generally, inferences) are explanatory devices we use to increase or communicate our understanding. We can develop a measure of relative 'cognitive content' for concepts, given Hegel's theory: a concept with little cognitive content will play a small role in only a few explanatory syllogisms; a concept with a great number of conceptual connections to other concepts

5 Richard Aquila, in his excellent article, "Predication and Hegel's Metaphysics," Kant Studien 64 (1973): 231-45, argues convincingly that besides this epistemological problem with mere referring expressions, Hegel also takes there to be a fundamental metaphysical problemnamely, when taken seriously, the idea of a pure referring expression seems to commit us to the idea of a pure referent, what we now call a bare particular. Hegel takes bare particulars to be nonsensical. The epistemological and metaphysical dimensions of referring expressions can be kept separate for our purpose, though. 
will play an important role in a number of illuminating explanatory inferences. Concepts, but not names, have cognitive content. ${ }^{6}$

Names are not similarly embedded within a complex web of inferential relationships, or to the extent that they are, they lose the character of a pure referring expression and begin to have the conceptual content characteristic of predicates. There has been a long debate over whether proper names have senses or not, but what John Searle has called the "classical" account insists that they do not.7 There are problems generated by such a position, but it seems clear that Hegel agrees with Mill in accepting a version of this "classical" theory of proper names. The lack of a sense is, at least in part, due to the fact that a name is not embedded in a network of conceptual relations in the way predicates are. Arguments to the effect that proper names do have senses often depend upon the fact that certain names do indeed acquire some, perhaps illdefined, "conceptual" relations with some predicate terms. ${ }^{8}$ Proper names are bestowed totally arbitrarily (at least as far as a logician is concerned); in order to be given a certain name there are no criteria the object must satisfy, whereas in order for a certain predicate to be applied, there are (often highly complex) criteria that must be satisfied. Again, names, unlike descriptions, do not tell us how to individuate the objects referred to, except insofar as there are certain conventions about reserving certain (kinds of) names for certain kinds of objects: "language, as the work of the understanding, says only what is universal, except for the name of an individual object; the individual name, however, is something meaningless [Sinnloses] in the sense that it doesn't express a universal and appears as something simply posited, arbitrary, for the same reason that proper names [Einzelnamen] can be arbitrarily assumed, given or even changed" (WdL I: 104-5, my trans.; SL, 117 ).

Thus, names do not have cognitive content according to Hegel; only predicates have such content.9

${ }^{6}$ A notion of 'cognitive content' is helpful not only in understanding Hegel's theory of the role of reference, but also in understanding what he is getting at when he demands that philosophers question the general truth of their categories. Untrue predicates are those with minimal conceptual content, that is, they are relatively unimportant in explaining and understanding the world. Thus, genus concepts tend to be truer than merely accidental predicates, and the concept of the concept, as the concept crucial to the understanding of the world, is the Truth, the Idea.

7 Some (e.g., Linsky) think that this position originated with Mill, but here Hegel antedates him. This position has recently received powerful new support from Kripke, Putnam, and others. See John Stuart Mill, A System of Logic (New York: Harper and Brothers, 1850), 20-27 (Vol. 1, Bk. 1, Chap. 2, 95); John Searle, "Proper Names and Descriptions," in Encyclopedia of Philosophy, edited by Paul Edwards, (New York: Macmillan, 1967), 6:487-91; Leonard Linsky, Names and Descriptions (Chicago: University of Chicago Press, 1977), 7; Saul Kripke, "Naming and Necessity," in Semantics of Natural Language, edited by Donald Davidson and Gilbert Harman (Dordrecht: Reidel, 1972); Hilary Putnam, "Meaning and Reference," The Journal of Philosophy 70 (November 8, 1973): 699-711.

8 Thus 'Aristotle' may not be equivalent to any specific set of descriptions, but if someone were to tell us that Aristotle neither studied under Plato, nor wrote the Metaphysics, nor engaged in biological research, nor founded the Lyceum ... we might not believe that he was indeed talking about the Aristotle we know and love.

9 The exegetical problems are actually thornier than 1 have painted them here. In the discussions of language in the Encyclopedia $\Upsilon_{4} 459-64 \mathrm{Hegel}$ treats all non-logical words as names. It 
3 .

It would now be convenient to assert that not only are names lacking in cognitive content, but so are demonstratives. But this would clearly do Hegel injustice. Hegel claims that demonstratives are universals; he does not claim that names are. Rather, demonstratives are a limit case of cognitive content, in that they have as little as possible.

Definite descriptions seem clearly to have some cognitive content: they characterize the object, allowing one to make certain inferences about the object based on the characterization. Most definite descriptions require relativization to a context in order to sort out the reference made. Demonstratives are similarly, though more obviously, context dependent. In a pure demonstrative reference seemingly all characterization of the object has dropped away, and it is the context alone (with perhaps help from a gesture) that supposedly suffices to fix the reference. But that context will specify certain characteristics that the demonstrated object should have, just as the predicates in the definite description did.

Descriptive reference is mediated by universals, by predicates. Hegel's position is that demonstrative reference is in the same boat: it is not different in kind from descriptive reference. Thus, we can grant Hamlyn that 'this' is not a predicate and yet maintain that it does have something of the universal about it.

Note the similarities demonstratives have with singular descriptive phrases:

1. In both, a change in context can easily produce a change in reference. 'The tallest man in the room' will refer to different people in different rooms, and, if the occupants of a room change, it may easily acquire a new reference in the same room. Here the reference depends upon the satisfaction of certain criteria, and the thing that satisfies the criteria is referred to, whatever it is. This is not the case for names-at least given a Millian theory of names. 'This', 'here', and 'now' also change reference as the context changes. Again this is a matter of the satisfaction of certain criteria (e.g., saliency in the environment), but these criteria are often so minimal that it is difficult for them not to be satisfied. How a demonstrative refers is more similar to how a description refers than to how a name refers.

2. Descriptive reference invokes a conceptual scheme allowing one to make certain inferences about the object. 'The tallest man in the room' allows one to make infer-

\footnotetext{
seems evident that, whether or not it was his considered view, he was strongly tempted by a 'twoname' theory of judgment. Here he again shows affinities to Mill. Furthermore, in common with other exponents of the "new way of ideas," Hegel took such words to name ideas (or as he called them, representations; see $\Upsilon_{4} 459$ and 461 ). Yet he distinguishes the names available in a language from the "formal factor in language," which is the "work of the understanding" and "gives rise to what is grammatical" (\$459). Actually this theory of names may have saved Hegel from the difficulties that a two-name theory of judgment must otherwise fall into. Hegel recognizes that grammatical structure makes a very important contribution beyond anything that the vocabulary itself can provide. This allows him to treat subjects and predicates, even if both are names, as differently as their grammatical roles. Cf. P. T. Geach, "History of the Corruptions of Logic," Logic Matters, 44-61.
} 
ences about the genetic make-up of the object talked about, its approximate spatial location, and, if we allow what can be inferred with some probability, we can conclude a great deal more. The doctrine of meaningless names will allow no inferences on the basis of a name alone. Certain demonstratives, however, do carry with them license to make some inferences. 'Now' indicates that what is being referred to is a time; 'here' indicates that a place or area is being referred to. Nevertheless, it is obvious that the inferences one can make on the basis of demonstrative reference alone are very minimal; this supports the thesis that they have only minimal cognitive content.

3. The definite description rubric, 'the , requires completion with some predicate expression. The demonstrative rubric 'this ___' admits such completion. But it does not make sense to talk of completing a name.

4. A point which Hegel seems not to have noticed, but which adds extra support, is that both definite descriptions and (some) demonstratives can have plural forms (e.g., 'the men in the elevator' and 'these') but names cannot. ${ }^{10}$

Much of what I have said about demonstratives, however, can also be applied to proper names, for they too shift reference from context to context. 'John Smith' names many different people, and which person is in fact picked out in a specific utterance depends upon contextual factors. Names also tend to offer clues to some characteristics of the referent: 'John Smith' will most likely name a human male in any of its occurences, 'Rover' a dog, etc. Still, though there are conventions correlating certain names with certain kinds of objects, these conventions are much looser and without the normative force of conventions governing predicates and demonstratives. It is difficult to state exactly what the differences between names and other expressions comes down to, but it is clear what Hegel recognized such a difference.

The difference between names and demonstratives might be summed up as follows: Names are too determinate in their mode of reference to characterize what they refer to; pure names tell us nothing about the object, because all they do is refer to it. Demonstratives, on the other hand, are too indeterminate to characterize the object of reference in a conceptually useful way; they tell us nothing about the object other than where to start looking for it. " Names and demonstratives are at opposite ends of a spectrum: names can refer to one and only one thing, but demonstratives can refer to anything at all. Yet neither has significant cognitive content, neither gives any kind of intrinsic characterization of the object.

4 .

I have shown that Hegel does not deny that we can refer to particulars. Knowledge of particulars depends upon the ability to refer to them, for we certainly could not know

10 We do say things like 'There were three Rockefellers at the concert'. Such pluralizations are either equivalent to statements of the form 'There were so many things called ____, or depend upon the names being doled out in accordance with certain non-linguistic criteria, thus removing them from the category of pure Millian names in which we are interested.

11 The context probably provides us with a sortal that tells us what sort of thing we are looking for. But this is presupposed, not said. 
of something that we could not even refer to. Many thinkers have been seduced into believing that different modes of reference are correlated with different modes of epistemological access. The advantage of such a position is that the theory of meaning and the theory of knowledge then exhibit elegant and important parallels.

This raises the question of whether Hegel assumed there to be a correlation between modes of reference and modes of epistemological access. A comparison with Russell will be instructive, for there is much to be learned from the late, lamented Lord, if only from the error of his ways. Between 1905 and 1913 (or later) Russell never shook the idea that for non-logical terms meaning was, in the last analysis, reference. For our sentences to be meaningful they had to consist ultimately of (1) logical words, which determined the logical form of the sentence, and (2) non-logical words, which successfully referred either to particulars or universals, depending on the word. In order to know a truth, Russell argued that we must first have knowledge of the components of the truth. Thus, in order to make our knowledge of truths intelligible, there had to be a form of knowledge prior to any knowledge of truths. Knowledge by acquaintance fills just this role. Just as the meaningfulness of a sentence is guaranteed by the fact that all its non-logical words denote (and that it is well-formed, of course), our knowledge of a truth presupposes knowledge of the constituents of the judgment, a different and immediate form of knowledge. ${ }^{18}$

That universals are things with which we can be directly acquainted is no longer a very popular view. Hegel too would reject the reification of universals, for it is an almost too perfect exemplification of the approach he insists is common to all "philosophies of the understanding." The meaning of a predicate is not some thing-like universal that it names. ${ }^{13}$ In contrast to Russell, Hegel took predicate terms to be verbs, not covert names. If one holds such a theory of universals, there is no need and no use for the idea of acquaintance with a universal in order to understand this part of our knowledge of truths. ${ }^{14}$ Indeed, since predicates do not refer, a correlation between reference and epistemological access will not explain the cognitive role of predicates.

What role do names and demonstratives play in knowledge? In the Russellian

12 Russell often talks as if the very things with which we are acquainted are constituents of the judgment, to which should be contrasted Hegel's insistence that we cannot say the thing itself. See Russell's Problems of Philosophy (Oxford: Oxford University Press, 1912), chapters 3, 4, and 12; "On Denoting" in Logic and Knowledge edited by Robert C. Marsh (New York: Macmillan, 1956) $55-56$.

13 Actually, as 1 have already pointed out, for Hegel the 'meaning' of a predicate word is a 'universal' that it 'names'-namely, the thought in the mind of the speaker. The thought's meaningfulness is not itself derived from the fact that it names some universal which leads a thing-like mode of existence in some nebulous Platonic heaven. Furthermore, Hegel insists that thought is primarily an activity, thinking. Having a certain thought is thinking a certain way. The verbal nature of the universal is retained.

14 Our knowledge of universals is ultimately like an agent's knowledge of what he is doing, which is not at all like acquaintance. See my paper "Hegel on Thought and Representation," Idealistic Studies 17 (May 1987):123-32; also Charles Taylor, "Hegel and the Philosophy of Action," Hegel's Philosophy of Action, ed. Lawrence S. Stepelevich and David Lamb (Atlantic Highlands, N.J.: Humanities Press, 1983). 
paradigm - and here many people still agree with him-singular reference guarantees that our knowledge really does hook up with the world. Russell was convinced that there had to be some place where the hookup was unbreakable in order for knowledge to be possible. In acquaintance knowledge is directly and immediately related to the world. Russell believed that the only logically proper names were demonstratives referring to the objects of direct acquaintance: sense-data, memories, the self, and universals.

How Hegel would reply to Russell should now be clear: direct acquaintance is not necessary to guarantee that knowledge hooks up with the spatio-temporal world. Demonstrative reference is not reference unmediated by universals; its basic form is that of a description, yet its conditions for success are so meager that it does guarantee a sufficient hookup with the natural world. ${ }^{15}$ To think of demonstratives as names is simply to misconstrue them.

But, according to Hegel, names do play a role in connecting our thoughts with the world. Yet, the reference relation is not itself cognitive, and names themselves contain no information. Having a name in mind is evidence of knowledge of an object only if it can be used to make true judgments about the object. Russell had not fully learned that words are primarily components of judgments and gain meaning only within a judgment. Instead, he insisted on looking for an independent and self-subsistent meaning and epistemological significance for all non-logical constituents of a proposition. But the fundamental sort of knowledge is knowledge of truths (in Russell's sense), and any knowledge of things is (consists in) a knowledge of truths about these things. Any other, more direct relation we may have to the thing is not a cognitive relation.

\section{5 .}

To present a full picture of the role in knowledge that Hegel assigns to singular referential devices, I must point out one further thesis Hegel accepted: In true knowledge, no reference to any individual occurs. This is a sense in which it is true that Hegel denies that there is knowledge of individuals. But this is true only of the very highest form of knowledge, absolute knowledge. This form of knowledge is experienced inchoately in Art and Religion and achieved explicitly only in Philosophy, when we understand the world, as it were, from a "God's-eye point of view." To see why absolute knowledge makes no mention of individuals, we must explore the connection between reference and the realm of the finite, for it turns out that reference by individuals to other individuals is an artifact of the finite.

I will first argue that the highest form of knowledge, absolute knowledge, cannot, according to Hegel, contain any reference to individuals per se; I will then return to my main point and show why it is the case that the phenomenon of individual reference in human language is nonetheless indispensable.

Like most of his predecessors, Hegel believed that there are different degrees of

is Although David Kaplan would probably not find the present treatment of demonstratives in the least congenial, he offers an interesting argument along similar lines that knowledge by acquaintance is not needed to insure reference (Demonstratives, unpub. ms.). 
being. Furthermore, Hegel and others (among them Plato) held that there are degrees of knowledge corresponding to the degrees of being. Hegel held that the form of all knowledge is judgmental. He believed further that judgmental forms are capable of a hierarchical ranking based on the adequacy of the forms to the expression of the truth, that is, based on the adequacy of the forms to the articulation of the world.

Hegel also distinguished between judgments proper (Urteile) and propositions (Sätze), though the distinction is not clear. ${ }^{16}$ The most important thing about propositions (in Hegel's sense) is that they are essentially concerned only with a particular state of affairs and contain minimal theoretical baggage. Hegel says a proposition "contains a determination of the subject which doesn't stand in the relation of universality to the subject-some state or individual action or such; 'Caesar was born in Rome in such and such a year, waged war for 10 years in Gaul, crossed the Rubicon', etc. are propositions, not judgments." 17 However, when a proposition is "asserted on the strength of some reason or other," it would "partake of the nature of a judgment." 18 For in that case the particular facts are treated as universals: reason is always generic. The "relation of universality" that holds between the concepts within a judgment is a rational connection, such as to be expressed by or stand behind a rational inference.

This distinction is, I believe, parallel with the truth/correctness distinction mentioned earlier. Propositions are merely capable of correctness, judgments of truth. True knowledge-knowledge of the highest order-is knowledge of Truth (with a capital $T$ ), and therefore judgmental, not merely propositional in nature.

The ultimate upshot of Hegel's doctrines is that true knowledge is the pursuit of philosophy. Philosophical truths are unconditionally necessary and universal. Like the conditionally necessary and universal truths of empirical science, philosophical truths contain no reference to any particular-unless it be the "universal particular," the Absolute-and the true philosophical comprehension of the Absolute would never make essential use of direct singular reference to the Absolute.

Names and demonstratives do play a role in the cognitive, however. P. F. Strawson has argued that such devices are necessary elements of any empirically learnable and usable language. ${ }^{19}$ Oddly enough, Hegel would agree. The emphasis here, though, is on empirical. Reference is essential to the knowledge that finite beings have of the finite world, and since finite beings come to knowledge of the infinite through knowledge of the finite, reference is a necessary presupposition of all their knowledge.

In the Hegelian system the finite is that which is determinate through its contrast with other things external to it or separate from it. Thus, the finite comes in individualized chunks. Now the chunks are not, and could not be, mere individuals, bare particulars, but must exemplify universals. Names are the linguistic counterparts of individu-

${ }^{16}$ Cf. The Logic of Hegel, trans. W. Wallace (Oxford: Oxford University Press, 1892); Enzyhlopedie der philosophischen Wissenschaften, eds. F. Nicolin and O. Pöggeler (Hamburg: F. Meiner, 1959), ๆ 167. Hegel's Science of Logic, trans. A. V. Miller (London: Allen and Unwin, 1969), 626; Wissenschaft der Logik, ed. G. Lasson (Hamburg: F. Meiner, 1934), 2: 267.

17 Encyclopedia, 1167.

18 Science of Logic, 626.

19 "Singular Terms, Ontology, and Identity," Mind 65: 260 (October 1956): 451 . 
als; it is as impossible to have a language that consists solely of names as it is to have a world consisting of bare particulars. ${ }^{20}$

If names are the linguistic expressions of individuality per se, demonstrative reference is the linguistic counterpart of the essential contrastive relativity of individuals. This is perhaps a bit harder to see. Hegel takes the fact that finite things gain their identity within contrastive relationships to external things to indicate that finite things are "self-external," that is, that they are not totally self-determined in their nature and existence. Demonstrative reference is founded upon the fact that the user of the term is one thing in a context of many others. Whereas an everywhere, everywhen divinity (which, of course, could not be the Hegelian Absolute) could use names to refer to individuals, it could not sensibly use demonstratives. Demonstrative reference brings out the individuality of the knower as well as the known.

Reference is the necessary condition for locating or applying universals to individuals, and is thus a necessary condition for knowledge of the finite. Although no particulars would be referred to in absolute knowledge, an absolute knower must be able to use and understand singular references, for without such an understanding there could be no knowledge of the finite. And since in Hegel's view the finite is contained within the infinite, and not merely set over against it, a being without knowledge of the nature of the finite could not be said to have full knowledge of either the infinite or the Absolute. ${ }^{21}$

\section{Tufts University}

WiLLEM DE VRIES

so. This should not be taken to preclude the possibility of a Sellarsian Jumblese, for that consists of configured names, not just names.

21 The vague ideas which generated this paper jelled during a most helpful discussion with Lynn R. Baker, to whom I am very grateful. I have further profited from comments by my colleague, W. E. Kennick, from Sidney Shoemaker, Gilbert Plumer, and from colloquia audiences at the University of Massachusetts, Amherst, and the Pacific Division of the APA, where my helpful commentator was G. J. Mattey. 